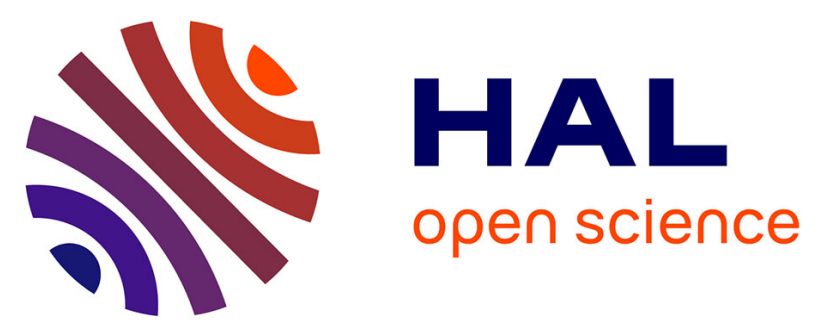

\title{
Going through the wine fining: Intimate dialogue between organics and clays
}

Pollyana Trigueiro, Silvia Pedetti, Baptiste Rigaud, Sebastien Balme, Jean-Marc Janot, Ieda M G Dos Santos, Régis Gougeon, Maria G Fonseca, Thomas Georgelin, Maguy Jaber

\section{To cite this version:}

Pollyana Trigueiro, Silvia Pedetti, Baptiste Rigaud, Sebastien Balme, Jean-Marc Janot, et al.. Going through the wine fining: Intimate dialogue between organics and clays. Colloids and Surfaces B: Biointerfaces, 2018, 166, pp.79 - 88. 10.1016/j.colsurfb.2018.02.060 . hal-01744266

\section{HAL Id: hal-01744266 https://hal.sorbonne-universite.fr/hal-01744266}

Submitted on 27 Mar 2018

HAL is a multi-disciplinary open access archive for the deposit and dissemination of scientific research documents, whether they are published or not. The documents may come from teaching and research institutions in France or abroad, or from public or private research centers.
L'archive ouverte pluridisciplinaire HAL, est destinée au dépôt et à la diffusion de documents scientifiques de niveau recherche, publiés ou non, émanant des établissements d'enseignement et de recherche français ou étrangers, des laboratoires publics ou privés. 


\section{Going through the wine fining: intimate dialogue between organics and clays}

Pollyana Trigueiro ${ }^{1,2}$, Silvia Pedetti ${ }^{1}$, Baptiste Rigaud ${ }^{3}$, Sebastien Balme ${ }^{4}$, Jean-Marc Janot ${ }^{4}$, Ieda M. G. dos Santos ${ }^{5}$, Régis Gougeon ${ }^{6}$, Maria G. Fonseca ${ }^{5}$, Thomas Georgelin ${ }^{7,8}$ and Maguy Jaber*1 $^{*}$

${ }^{1}$ Sorbonne Universités, UPMC Paris06, UMR 8220, Laboratoire d'Archéologie Moléculaire et Structurale, 4 place Jussieu, F-75005 Paris, France

${ }^{2}$ Materials Engineering Department of Paraíba Federal University, João Pessoa, Paraíba, Brazil ${ }^{3}$ CNRS Institut des Matériaux de Paris Centre (FR2482), 4 place jussieu, 75005 Paris, France ${ }^{4}$ Institut Européen des Membranes, UMR 5635, Université de Montpellier, ENSCM, CNRS, Place Eugène Bataillon, F-34095 Montpellier cedex 5, France

${ }^{5}$ Chemistry Department of Paraíba Federal University, João Pessoa, Paraíba, Brazil

${ }^{6}$ Univ. Bourgogne Franche-Comté, AgroSup Dijon, PAM UMR A 02.102,Institut Universitaire de la vigne et du vin Jules Guyot, rue Claude Ladrey, BP 27877, 21078 Dijon Cedex, France

${ }^{7}$ SorbonneUniversités, UPMC Paris06, UMR 7147, Laboratoire de Réactivité de Surface, 4 place Jussieu, F-75005 Paris, France

${ }^{8}$ Centre de Biophysique Moléculaire (CBM), CNRS, Rue Charles Sadron, 45071 Orléans, France

Corresponding author

*Maguy Jaber :maguy.jaber@upmc.fr

The paper has 6523 words and 6 figures and 2 tables. 


\section{ABSTRACT}

Wine chemistry inspires and challenges with its complexity and intriguing composition. In this context, the composites based on the use of a model protein, a polyphenol of interest and montmorillonite in a model hydroalcoholic solution have been studied. A set of experimental characterization techniques highlighted the interactions between the organic and the inorganic parts in the the composite. The amount of the organic part was determined by ultraviolet-visible (UV-VIS) and thermal analysis. X-ray diffraction (XRD) and transmission electronic microscopy (TEM) informed about the stacking/exfoliation of the layers in the the composites. Vibrational and nuclear magnetic resonance spectroscopies methods stressed on the formation of a complex between the protein and the polyphenol before adsorption on the clay mineral. The mobility/rigidity of the organic parts were determined by fluorescence time resolved spectroscopy. Changes in the secondary structure of the protein occured upon complexation with polyphenol on clay mineral due to strong interactions. Although not representating faithfully enological conditions, these results highlight the range and nature of mechanisms possibly involved in wine fining.

Keywords: adsorption, resveratrol, BSA, NMR, Fluorescence spectroscopy, wine, clay

The paper has 6523 words and 6 figures and 2 tables. 


\section{Introduction}

Proteins are present in wine in low concentrations, contributing weakly to their nutritive characteristics. Nevertheless, their presence in high proportion may affect the quality of the product, being responsible for the turbidity and time-instability of white wines. The proteins of wine are generally tolerant to the $\mathrm{pH}$ of the wine $(\mathrm{pH}=3-3.6)[1-3]$. Naturally occurring proteins of grapes, and in particular pathogenesis related (PR) proteins, have been shown to cause turbidity or haze formation in white wines, where the instability can be related to factors such as $\mathrm{pH}$ of the medium, ethanol content, ionic strength, temperature or concentration of the organic acids, tannins and polyphenolic compounds[4-6]. Therefore, it is necessary in the fining treatment to eliminate the risk of protein precipitation, which content can vary from 10 to more than 260 mg. $\mathrm{L}^{-1}[7,8]$. It must be noted though, that in Champagne, proteins can have a positive role on the foamability.

Polyphenols are responsible for the differences between white and red wine, especially in the determination of the color, body, flavor and structure of red wine[9]. Among the diversity of polyphenolic compounds, stilbenes and derivatives have been largely studied,in particular resveratrol (RESV), has antioxidant, bactericides, anti-inflamatory and vitamin properties, which are related to its protective effect against cardiovascular diseases[10].Even though it can also be found in food products and beverages such as peanut butter, mulberries and grape juice, Red wine is believed to be the main source of resveratrol in the human diet[11,12]. The phenolic compounds found in wines may vary according to their structure as, tannins, non-flavonoids and flavonoids. RESV (Figure 1 SI, in Supplementary information) is a flavonoid, natural pigment, which can be present in high concentration in grape skin but not in grape flesh, so red wine contains significant amounts of resveratrol compared to white wine, with concentration ranging from 0.1 to $3.0 \mathrm{mg} . \mathrm{L}^{-1}$, where its amount depends on the grape variety and the 
vinification process[13,14]. It has been reported in the literature that the complexation of resveratrol with macromolecules can modulate the expression of its bioviability and stability as well as its antioxidant effect[14,15].

Different fining agents in winemaking are reported in the literature, but clay minerals rich in montmorillonite such as bentonite, remain heavily used for white wines. Bentonite behaves as stabilizer by adsorbing proteins in wine wich typically have isoelectric point (IP) between 3 and 9 and a MW between 20-70 KDa[16]. Montmorillonite displays a layered structure of type 2:1, ideally formed by two sheets of tetrahedrally coordinated silicon linked through a sheet of octahedrally coordinated aluminum. $\mathrm{Al}^{3+}$ and $\mathrm{Mg}^{2+}$ generally occupy octahedral sites, whereas Hydrated exchangeable $\mathrm{Na}^{+}$or $\mathrm{Ca}^{2+}$ cations are present in the interlayers to balance the negative layer charge[17-19].

Adsorption of proteins onto clay minerals has been widely reported in the literature[20-22]. It may involve several types of physical and chemical interactions such as cation exchange, electrostatic forces or hydrogen bonding, on the interlayer surface of clay minerals, on the edges or both. The positive charge of the protein when the $\mathrm{pH}$ is below the IP allows the adsorption on the negatively charged surface of montmorillonite due to electrostatic forces. Various possible mechanisms can describe the interaction between proteins and clays: intercalation, exfoliation or both [20]. Extensive penetration of protein chains into the interlayer space of clays can lead to exfoliation or delamination of the silicate layers[23-25].

The use of clay minerals for the fine treatment of wine may induce not only adsorption of the protein but also of other molecules. As reported in the literature, there may be a decrease in the amount of resveratrol in the wine due to interactions with fining agents[26,27] or an interaction of resveratrol with the protein due to electrostatic forces, hydrophobic interactions and/or hydrogen bond between these two compounds[28,29]. 
Bovine serum albumin (BSA, Figure 2 SI in Supplementary information) with MW of $66.5 \mathrm{KD}$ a is used as model protein for this study. It is characterized by globular structure and is the most abundant soluble plasma protein with a typical circulating concentration of $0.6 \mathrm{mmol} . \mathrm{L}^{-1}$. In addition, it is extensively used in biochemical studies due to its wide availability and high structural resemblance with human serum albumin[30,31]. Resveratrol has a strong interaction with albumin. Indeed, several molecules can be bound to the hydrophobic pocket of albumin with an affinity constant around $2.10^{4} \mathrm{M}^{-1}$ or $5.10^{4} \mathrm{M}^{-1}$. This binding occurs via both hydrophillic and hydrophobic interactions and/or hydrogen bonding[30,32,33].

The aim of the present work is to investigate the co-adsorption of a model protein, the BSA, and a polyphenol of interest, resveratrol, onto a synthetic montmorillonite (Mt)in an hydroalcoholic solution, in order to investigate, via a multi-technical approach, the presence and the nature of interactions between the clay mineral, the protein and the polyphenolic compound present in wine.

\section{Experimental part}

\subsection{Materials}

Bovine Serum Albumin (>99\%) and resveratrol (>99\%) were purchased from Sigma-Aldrich. Potassium phosphate monobasic (>99\%) buffer 0.1M and ethanol (solvent system) were used to solubilize the protein and polyphenol. Anapproximation of amodel wine solution was made with the mixture of $25 \%$ distilled water, $50 \%$ phosphate buffer and $25 \%$ ethanol (ratio v/v) at $\mathrm{pH}=4.5$ (solvent system used in BSA solution and RESV solution). For the synthesis of the montmorillonite,the following reagents were used: Aerosil 130 (Evonik Industries) as source of silica, Bohemite (AlOOH) 74\% $\mathrm{Al}_{2} \mathrm{O}_{3}$ (Sasol Germany), Magnesium acetate tetrahydrate (Sigma-Aldrich), Sodium acetate (Sigma-Aldrich) and hydrofluoric acid.

\subsection{Synthesis of montmorillonite}


For the synthesis of sodium montmorillonite, the reagents were mixed in the following order: deionized water, hydrofluoric acid and the sources of interlamellar cation: sodium acetate, magnesium acetate, alumina and silica. The hydrogels were aged under stirring at room temperature for $2 \mathrm{~h}$ and then were autoclaved for reaction at $220{ }^{\circ} \mathrm{C}$ for $72 \mathrm{~h}$. The autoclaves were cooled to room temperature and the products were washed thoroughly with distilled water and centrifuged. The solids were then dried at $50{ }^{\circ} \mathrm{C}$ for $24 \mathrm{~h}[34,35]$.

\subsection{Adsorption of proteins}

Adsorption experiments were carried out by adding dropwise BSA solution, dissolved in the above described solvent system, in an aqueous suspension of the clay mineral (1.2mg.mL $\left.{ }^{-1}\right)$. The initial concentration of BSA $\left(1.0 \mathrm{mg} \cdot \mathrm{mL}^{-1}\right)$ was determined before addition of montmorillonite. The mixture was stirred at room temperature for 4 hours. After that, the suspension was centrifuged at 2700rpm for 8 minutes. Both supernatants and solids were collected and analyzed. Solids were washed with aqueous solution to remove weakly adsorbed BSA and dried at room temperature. The amount of protein remaining in the supernatant was determined by UV-Vis spectroscopy considering the absorption maximum wavelength at 281 $\mathrm{nm}$. All measurements were performed in triplicate. The concentration of adsorbed protein on montmorillonite was determined by:

$\Gamma_{\mathrm{t}}=\frac{\mathrm{V}\left(\mathrm{C}_{0}-\mathrm{C}_{\mathrm{t}}\right)}{\mathrm{m}}$

where $\mathrm{V}$ is the total volume of the protein solution, $C_{0}$ is the initial concentration of protein, $C_{t}$ is the concentration of protein in supernatant at time $t$, and $\mathrm{m}$ is the mass of the clay mineral. With $V(\mathrm{~mL}), C_{0}$ and $C_{t}\left(\mathrm{mg} \cdot \mathrm{mL}^{-1}\right)$, the interfacial concentration $\Gamma_{\mathrm{t}}$ of protein is given in $\mathrm{mg}$ of protein per mg of clay mineral (mg.mg $\mathrm{Mt}^{-1}$ ).

\subsection{Adsorption of resveratrol onto sodium clay}


The polyphenol adsorption experiments were performed as described for the protein. The initial concentration of RESV (0.5 mg.mL ${ }^{-1}$ ) was determined before addition of montmorillonite. The amount of resveratrol remaining in the supernatant was determined by UV-Vis spectroscopy with absorption at $306 \mathrm{~nm}$.

\subsection{Simultaneous adsorption of polyphenol and BSA onto sodium clay}

BSA (1.0 mg.mL $\mathrm{m}^{-1}$ ) was dissolved in solution of the above described solvent system. Separately, resveratrol with a concentration of $\left(0.5 \mathrm{mg} \cdot \mathrm{mL}^{-1}\right)$ was dissolved in a solution of the above described solvent system. Then, the solution containing RESV was added dropwise to the BSA solution that was then kept under constant stirring for 2 hours. Resulting solution was added dropwise to the aqueous suspension of the clay mineral with a of concentration $1.2 \mathrm{mg} \cdot \mathrm{mL}^{-}$ ${ }^{1}$ under constant stirring for 2 hours. The resulting mixture was stirred for 4 hours at room temperature. The resulting slurry was washed and centrifuged for removal of excess of protein and polyphenol. The resulting solid was separated by centrifugation and dried at room temperature.

\subsection{UV-Visible}

Ultraviolet-visible (UV Vis) absorption spectra were recorded using an Ocean View Optics spectrometer DH-2000-BAL. The light source was a Deuterium and Halogen lamp, equipped with $400 \mu \mathrm{m}$ diameters optic fibers, coupled with CUV $1 \mathrm{~cm}$ cuvette holder. Spectra were acquired by Ocean View Spectroscope Software. The absorbance wavelength range was from 250 to $900 \mathrm{~nm}$.

\subsection{X-ray diffraction (XRD)}

Powder X-ray diffractograms were recorded using D8 Advance Bruker-AXS Powder X-ray diffractometer with $\mathrm{CuK}_{\alpha}$ radiation $(\lambda=1.5405 \AA)$. The diffractions patterns were measured 
between $5-70^{\circ}(2 \theta)$ with a scan rate of 0.5 deg. $\mathrm{min}^{-1}$. The active area of the detector was limited as much as possible in order to reduce the background scattering at low angle between $1-10^{\circ}$ (20). Samples were kept $72 \mathrm{~h}$ before measurements under controlled humidity.

\subsection{Transmission electron microscopy (TEM)}

TEM study of the samples was performed on a JEOL 2010 microscope, 200kV LaB6 coupled Orius camera, from Gatan Company. Samples in the form of bulk powders were suspended in ethanol and then deposited on 400 mesh copper grids covered with an ultrathin carbon membrane of $2-3 \mathrm{~nm}$ thickness.

\subsection{Attenuated Total Reflectance (ATR) Infrared spectroscopy}

Fourier transform infrared spectroscopy (FTIR) of the solid samples was performed on Agilent Cary 630 FTIR spectrometer using Agilent diamond attenuated total reflectance ATR technique. Spectra were acquired on the 4000 and $650 \mathrm{~cm}^{-1}$ range and processed with the Microlab FTIR Software (Agilent Technologies).

\subsection{Thermal analysis}

Thermal analyses were carried out using a Q600-1694 SDT Q600 TA Instrument and TA Universal Analysis 2000, the heating rate was of $5{ }^{\circ} \mathrm{C} \cdot \mathrm{min}^{-1}$ from $25^{\circ} \mathrm{C}$ to $1000{ }^{\circ} \mathrm{C}$, with flow rate of $10 \mathrm{~mL} \cdot \mathrm{min}^{-1}$, in air atmosphere.

2.11. Solid State Cross-Polarization Magic Angle Spinning Carbon 13 Nuclear Magnetic Resonance $\left({ }^{13} \mathrm{C}\right.$ CP-MAS Solid state nuclear magnetic resonance)

${ }^{13}$ CCP-MAS NMR spectra were obtained on a Bruker Advance 500 spectrometer operating at $\Omega_{\mathrm{L}}=500 \mathrm{MHz}\left({ }^{1} \mathrm{H}\right)$ and125 $\mathrm{MHz}\left({ }^{13} \mathrm{C}\right)$ with a $4 \mathrm{~mm} \mathrm{H}-\mathrm{X}$ MAS probe. Chemical shifts were calibrated using the $\mathrm{CH}_{2}$ signal of adamantane (38.52 ppm) as an external standard. The CP 
spectra were acquired with a MAS rate of $14 \mathrm{kHz}$, an acquisition time of $40 \mathrm{~ms}$, a ramp-CP contact time of $1 \mathrm{~ms}$, a $1 \mathrm{~s}$ recycle delay and with a ${ }^{1} \mathrm{H}$ spinal 64decoupling sequence. The number of scans to obtain the spectra depending on the $\mathrm{S} / \mathrm{N}$ obtained for each sample. Spectra were processed with a zero filling factor of 2 and with an exponential decay corresponding to $25 \mathrm{~Hz}$ line broadening. Only spectra with the same line broadening were directly compared. The decomposition of the spectra was performed using Dmfit-2015 software.

\subsection{Fluorescence spectroscopy}

Steady-state and time-resolved fluorescence spectra were obtained by the time-correlated single-photon counting technique. The excitation wavelength was achieved using a SuperK EXTREME laser (NKT Photonics, model EXR-15) as a continuum pulsed source combined with SuperK EXTEND-UV super continuum (NKT Photonics, model DUV); the wavelength was selected by coupling to a monochromator (Jobin-Yvon H10). The repetition rate was set to $19.4 \mathrm{MHz}$; the excitation pulse duration on this device is around 6 ps (full-width-at-halfmaximum, FWHM). The emission of fluorescence is detected, after passing through a polarizer oriented at the magic angle $\left(54.73^{\circ}\right)$ to the polarization of the excitation, through a double monochromator Jobin-Yvon DH10 on a hybrid PMT detector HPM-100-40 (Becker \& Hickl). The instrumental response function of the equipment was measured by using a dilute suspension of polystyrene nanospheres in water (70 nm of diameter) as a scattering solution; it was typically about 130-160 ps FWHM. Decays were collected at a maximum counting rate of 17 kHz into 4096 channels using an acquisition card SPC-730 (Becker \& Hickl). This limiting count rate was achieved by dilution in water of the sample and after sedimentation of the suspension in order to minimize as much as possible the scattering of the particles. The time per channel was set around 6 ps ch-1 in order to fit a full decay in the experimental time window. Decay analysis was performed using a Levenberg-Marquardt algorithm. For the analysis, the fluorescence decay law at the magic angle IM(t) was assumed as a sum of exponentials. We 
assumed a Poisson distribution of counts in the calculation of the $\chi^{2}$ criterion; residual profiles and autocorrelation function as well as Durbin-Watson and skewness factor were used in order to estimate the quality of the adjustment. The number of exponentials used for the fit was increased until all the statistical criterions were improved. All details about calculation of both lifetime are given elsewhere[36].

\section{Results and Discussions}

\subsection{BSA and RESV adsorption onto sodium clay}

The UV-Vis spectra of the BSA and RESV before and after adsorption on montmorillonite are shown in Figure 1. The intensity of the band maxima of the BSA in Figure 1(a) at $281 \mathrm{~nm}$ decreases after adsorption on montmorillonite. The RESV showed band maxima at $306 \mathrm{~nm}$ as we can see in Figure 1(b) and follows the same trend as BSA. The influence of the contact duration was also investigated. The adsorption kinetics $\left(C_{0}=1.0 \mathrm{mg} \cdot \mathrm{mL}^{-1}\right)$ curves are reported in Figure 3 SI in Supplementary information and similar behavior was observed for both protein and resveratrol.
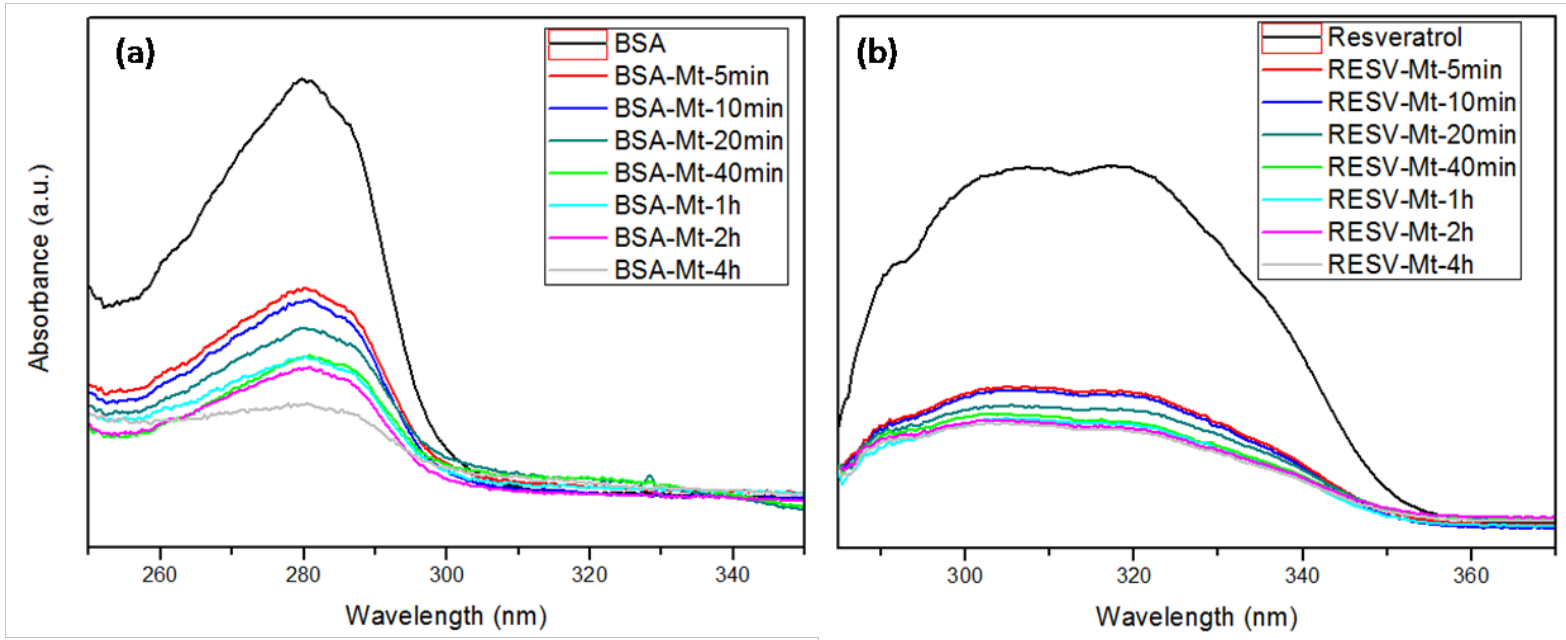

Figure 1. UV-Vis absorption spectra of supernatant solution during adsorption reaction of BSA (a) and RESV (b) on montmorillonite. Experimental conditions: BSA (1.0 mg. $\mathrm{mL}^{-1}$ ), RESV (1.0 mg. $\left.\mathrm{mL}^{-1}\right), \mathrm{Mt}(1.0$ $\mathrm{mg} \cdot \mathrm{mL}^{-1}$ ) in a buffer phosphate solution at $\mathrm{pH} 4.5$ and ethanolic solution in ratio of $25 \%$. 
In the present study, the Langmuir isotherm model adequately describes the adsorption data, that are as widely reported for protein adsorption on clay minerals[37]. The Langmuir isotherm of pseudo-second-order model can be linearized in agreement to the equation:

$\frac{t}{\Gamma_{t}}=\frac{1}{k_{2} \Gamma_{e}^{2}}+\frac{1}{\Gamma_{e}} t$

where $\Gamma_{t}$ and $\Gamma_{e}$ is the interfacial concentration (mg.mg Mt $_{\text {) }}$ at time $t$ and at the equilibrium respectively, $k_{2}$ is the equilibrium rate constant of pseudo-second-order adsorption (mg $\mathrm{mg}_{\mathrm{Mt}}{ }^{-}$ $\left.{ }^{1} \cdot \mathrm{min}^{-1}\right)$.

Pseudo-second order equation were used to research the adsorption kinetic behavior for protein and polyphenol on montmorillonite, reported in Figure 4 SI in Supplementary files. The slope and intercept of the plot of $t / \Gamma_{t}$ versus t were used to calculate the $K_{2}$ rate constant. Values of the $\Gamma_{e}$ (interfacial concentration maximum) and $\mathrm{K}_{2}$ (adsorption kinetic constant) are reported in Table I. $\mathrm{K}_{2}$ values indicates affinity of the protein and polyphenol for the inorganic support and in the present case the value of $\mathrm{K}_{2}=0.16$ obtained demonstrates the high affinity of the BSA with the surface of the montmorillonite [20,38].

Table I. Kinect parameters obtained by Langmuir isotherm for BSA and resveratrol adsorption on montmorillonite.

\begin{tabular}{|l|l|l|}
\hline & Resveratrol & BSA \\
\hline$\Gamma_{e}\left(\mathrm{mg} \mathrm{mg}_{\mathrm{Mt}^{-1}}\right)$ & 0.32 & 0.87 \\
\hline $\mathrm{K}_{2}\left(\mathrm{mg} \mathrm{mgt}^{-1} \cdot \mathrm{min}^{-1}\right)$ & 1.90 & 0.16 \\
\hline
\end{tabular}

\subsection{Localization of the organic molecules in the clay mineral}

XRD patterns of the montmorillonite and all hybrids composites are reported in Figure 2. The X-Ray pattern of the raw montmorillonite shows typical reflections characteristics of the dioctahedral smectite $\left(\mathrm{d}_{060}=0.149 \mathrm{~nm}\right)$ [38,39]. The $\mathrm{d}_{001}$ value is about $1.26 \mathrm{~nm}$ before 
adsorption corresponding to the thickness of the layer and the presence of hydrated sodium in the interlayer space. Upon adsorption of the protein, the $\mathrm{d}_{001}$ peak disappears while the other characteristic reflection peaks of montmorillonite remained intact, hence the hypothesis of a possible partial exfoliation or delamination can be considered [20]. After adsorption of resveratrol, the interbasal spacing of the clay mineral cannot be detected, making difficult to evaluate the degree of intercalation of the polyphenol which may possibly be non-uniformly distributed between the montmorillonite layers. After adsorption of the BSA and RESV together, it is not possible to measure the inter-basal spacing $d_{001}$, which may suggest partial or total exfoliation of the montmorillonite layers upon inclusion of the protein and the polyphenol. These studies will be complemented with TEM analysis. Presence of the crystalline phase of resveratrol is common, characteristic peaks of the drug at $2 \theta=16.5,22.6,23.8$ and $30.1^{\circ}$ were observed in RESV-Mt sample and at 16.4, 22.5 and $28.5^{\circ}(2 \theta)$ in the BSA-RESV-Mt. Shifts in the $\mathrm{d}_{(001)}$ reflexion in the RESV-Mt sample is probably due to a different hydration state of the interlayer space. In the pattern of BSA-Mt sample, the (001) reflexion is not visible due probably to an heterogeneity in the layer stacking or a delamination of the layers $[40,41]$. These results will be confirmed by TEM.

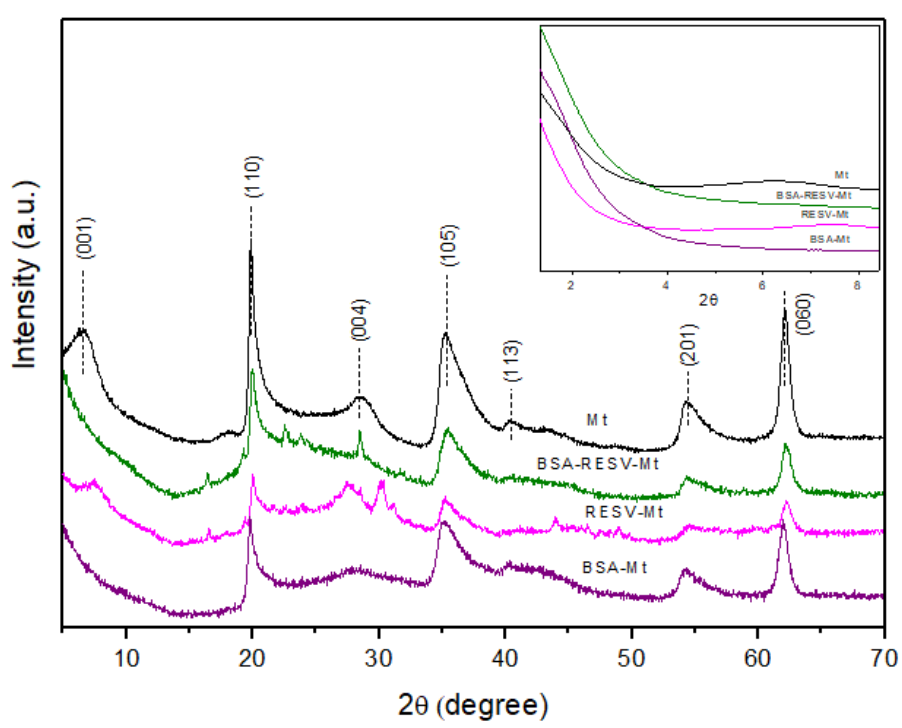


Figure 2. XRD patterns diffractograms and insert at low angle $1-10^{\circ}(2 \theta)$ of the montmorillonite (black), BSA absorbed onto clay (violet), RESV absorbed onto clay (pink) and BSA-RESV-Mt composite (green).

\subsection{Transmission electron microscopy (TEM)}

Transmission electron microscopy (TEM) micrographs show layered structures with alternate dark and bright fringes with a repeat length of $1.26 \mathrm{~nm}$ for the raw clay, synthetic clay without modification.

In Figure 3(a) and 3(b), after BSA adsorption on Mt, the measured $\mathrm{d}_{001}$ value reaches3.2 nm indicating the intercalation and partial delamination of the protein in the interlayer space of the Mt. After resveratrol adsorption, the d d001value varies from 1.5 to $1.85 \mathrm{~nm}$, attesting of the heterogeneous incorporation of resveratrol, in Figure 3(c) and 3(d), in agreement with the XRD results. The sample containing both resveratrol and BSA presented different populations of layers: some are exfoliated and others are intercalated with a d spacing of BSA-RESV-Mt composite varying between $2.96-3.9 \mathrm{~nm}$. From these results the incorporation of the BSA and RESV together is supposed to cause exfoliation of the clay mineral shown in Figure 3(e) and 3(f). 

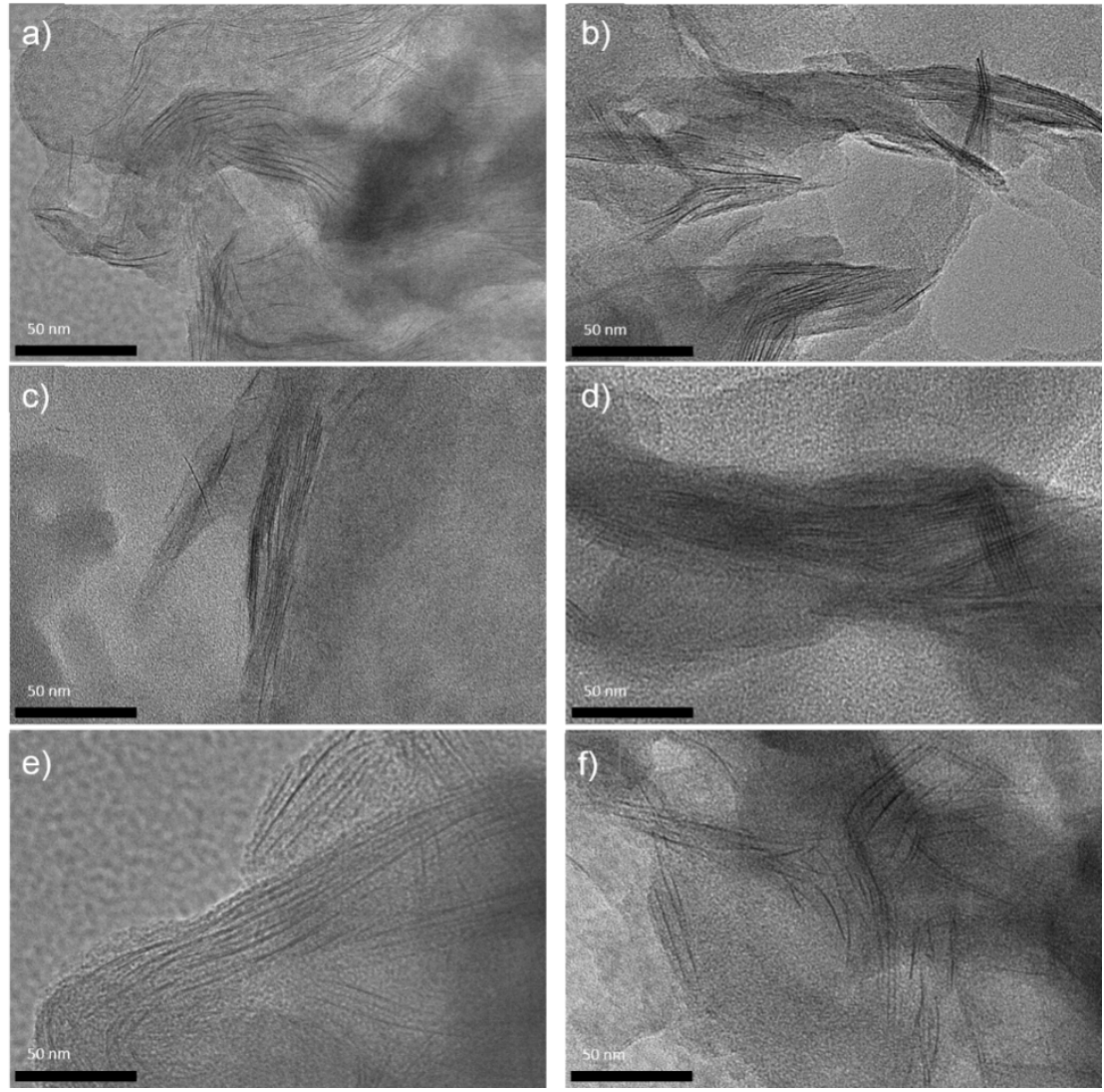

Figure 3. Transmission electron micrographs (TEM) of the BSA-Mt (a) and (b); RESV-Mt (c) and (d); BSA-RESV-Mt (e) and (f). Experimental conditions: BSA (1.0 mg.mL $\left.{ }^{-1}\right)$, RESV (0.5 mg. $\left.\mathrm{mL}^{-1}\right)$, Mt (1.2 $\mathrm{mg} \cdot \mathrm{mL}^{-1}$ ) in a buffer phosphate solution at $\mathrm{pH} 4.5$ and ethanolic solution in ratio of $25 \%$.

\subsection{Spectroscopic characterization}

Study of BSA and RESV conformation before and after adsorption onto clay mineral was performed using ATR-Infrared spectroscopy (Figure 4). The presence of the physisorbed water of montmorillonite is observed by the bending vibration at $1634 \mathrm{~cm}^{-1}$ [42] while the characteristic peak at $1015 \mathrm{~cm}^{-1}$ is due to stretching vibrations of the Si-O groups[43]. According to the literature[44-46] the spectral ranges for the most intense peaks for proteins occur in the region $1700-1600 \mathrm{~cm}^{-1}$ and $1600-1500 \mathrm{~cm}^{-1}$ that are assigned to amide I and amide II vibrations, respectively. Infrared absorption of resveratrol showed three characteristics intense bands (Figure 4b) at $1606 \mathrm{~cm}^{-1}$ corresponding to C-C aromatic double band stretching, 
$1585 \mathrm{~cm}^{-1}$ band assigned to C-C olefinic stretching and the band observed at $1381 \mathrm{~cm}^{-1}$ corresponding to a ring C-C stretching[41,47].

Conformational changes of the structure of the BSA upon confinement onto montmorillonite were pointed. A shift in amide I and amide II bands from $1640 \mathrm{~cm}^{-1}$ to $1643 \mathrm{~cm}^{-1}$ and from 1521 $\mathrm{cm}^{-1}$ to $1525 \mathrm{~cm}^{-1}$ in Figure 4(a) were observed. This is consistent with the change in the secondary structure of the protein[22,48]. Upon adsorption of RESV onto Mt, we observed a spectral shift of characteristics bands of the RESV in Figure4(b) that move from 1606 to $1608 \mathrm{~cm}^{-1}$,from 1585 to $1589 \mathrm{~cm}^{-1}$ and from 1381 to $1386 \mathrm{~cm}^{-1}$. The significant shift of this last band corresponding to the ring $\mathrm{C}-\mathrm{C}$ stretching suggests the interaction of RESV with the Mt surface[41].

The absorption bands characteristic of the BSA-RESV-Mt composite are showed in Figure 4(c). Shifts from 1640 to $1648 \mathrm{~cm}^{-1}$ and from 1521 to $1524 \mathrm{~cm}^{-1}$ as well as increase in the intensity of the amide I and amide II bands of protein, respectively were observed. Changes from 1585 to $1588 \mathrm{~cm}^{-1}$ and from 1381 to $1388 \mathrm{~cm}^{-1}$ of the characteristics bands of resveratrol after interaction with BSA and montmorillonite were observed. This could be attributed to the presence of interactions between the protein and the polyphenol with montmorillonite or it may suggest the co-adsorption of resveratrol in the protein before interaction with the clay mineral. This information can be complemented with the fluorescence analysis. 

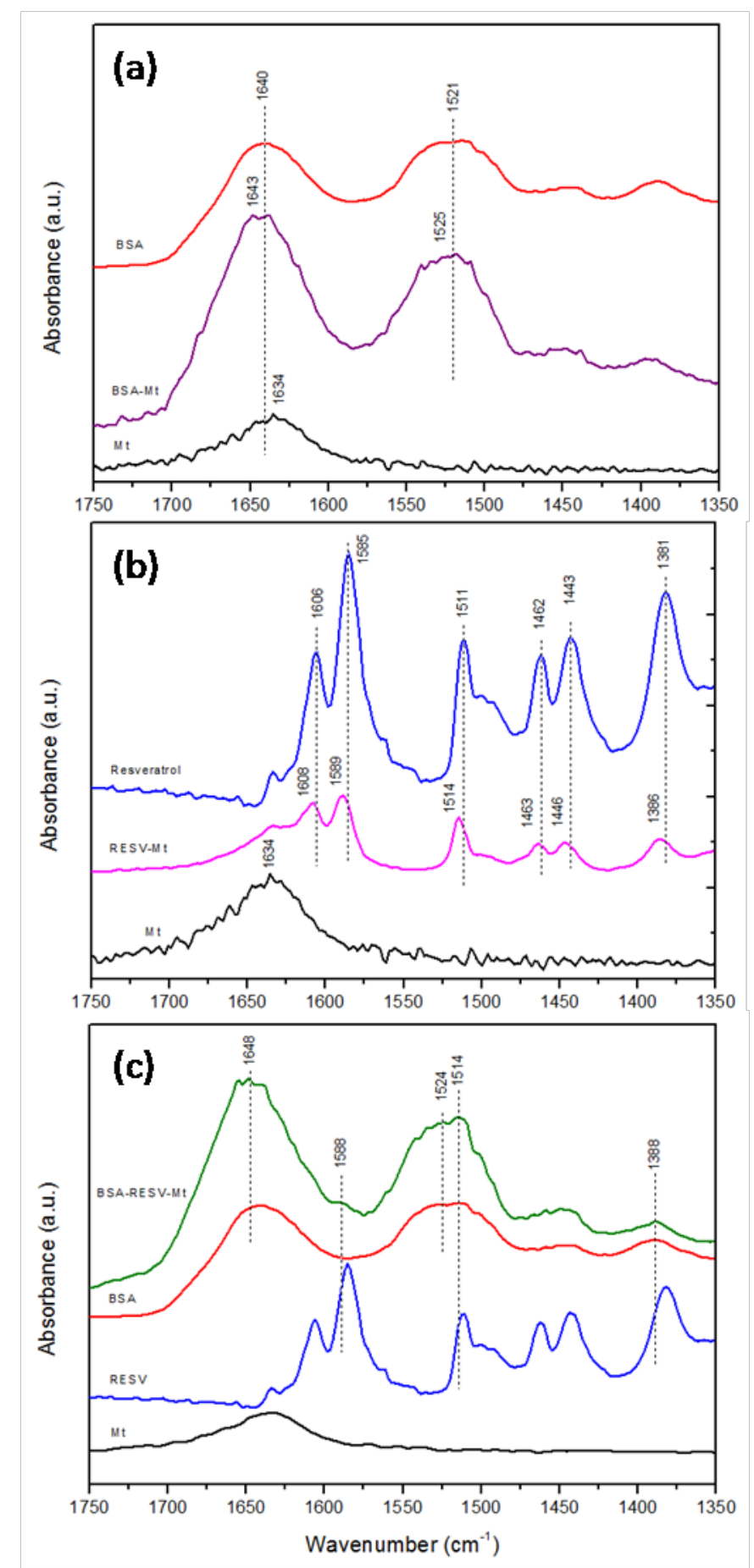

Figure 4. ATR-IR spectra of (a) free BSA and upon adsorption on Mt; (b) free RESV and upon adsorption onto $\mathrm{Mt}$ and (c) free BSA, free RESV and BSA-RESV-Mt composite.

\subsection{Thermogravimetric Analyses}


TG curve and their corresponding derivative of the montmorillonite are reported in Figure 5 SI in Supplementary files. The curve relative to montmorillonite alone is characterized by three steps of mass loss associated to endothermal events. The first one, at $82^{\circ} \mathrm{C}$ with weight loss of $8.6 \%$, corresponds to the release of water physically adsorbed on the surface, the weight loss of $1.4 \%$ at $184^{\circ} \mathrm{C}$ is due to the departure of the interlayer water molecules. Finally, two peaks at $428^{\circ} \mathrm{C}$ and $645^{\circ} \mathrm{C}$ are due to dehydroxylation with weight loss of about $3.5 \%[49]$.

Thermogravimetric analyses of BSA and RESV alone and of BSA-RESV-Mt composite were studied and reported in Figure 6 SI and Figure 7 SI in Supplementary information. DTG curve of free BSA exhibits a broad mass loss at $61^{\circ} \mathrm{C}$ related to dehydratation while two peaks observed at $275^{\circ} \mathrm{C}$ and $316^{\circ} \mathrm{C}$ are likely due to the polypeptide chain thermal decomposition of proteins that corresponds to 55\% mass loss. In addition, a second thermal decomposition step of the organic matter is observed between $450-650{ }^{\circ} \mathrm{C}$ (mass loss around of $40 \%$ ) with a maximum at $493^{\circ} \mathrm{C}$ and $617^{\circ} \mathrm{C}$, includes both the decomposition of the hard residues of the proteins[50]. The free RESV is thermally stable under air flow up to about $260^{\circ} \mathrm{C}$ and its degradation shows two maximum at $310^{\circ} \mathrm{C}$ and $549^{\circ} \mathrm{C}$, with a total mass loss around $90 \%$.

After adsorption of the protein on $\mathrm{Mt}$, an increase of the decomposition temperature for the BSA was observed, which occurs at $308^{\circ} \mathrm{C}$ and $537^{\circ} \mathrm{C}$ (mass loss $22 \%$ ). This is likely due to the changes in the conformational structure of the proteins upon interactions with the clay mineral. After adsorption of RESV on Mt, an increase in thermal stability of the polyphenol was observed with a maximum decomposition temperature of polyphenol at $428^{\circ} \mathrm{C}$, with a mass loss of $14 \%$. This may suggest intercalation or interactions of resveratrol in the external and/or internal surface of clay. The peak observed at $632^{\circ} \mathrm{C}$ with a mass loss of $2.6 \%$ is attributed to matrix dehydroxylation. 
Thermal analysis BSA-RESV-Mt composite showed mass loss peaks shifted with respect to single Mt composites, observed in Figure 7 SI in Supplementary files. The differential peaks at $46^{\circ} \mathrm{C}$ with mass loss of $18 \%$ and $219^{\circ} \mathrm{C}$ with mass loss of $3 \%$ correspond to the removal of physisorbed water and to the dehydratation of interlayer water, respectively. The progressive decomposition of the organic matter, with mass loss of 37\%, is indicated by the peaks maximum at $316^{\circ} \mathrm{Cand} 489^{\circ} \mathrm{C}$. The significant enhancement in thermal stability of the composites can be attributed to the exfoliation of silicate layers with intercalation of the protein and polyphenol complex preventing the fast decomposition of the products. The results obtained are similar to those observed in the adsorption tests.

\section{6. ${ }^{13} \mathrm{C}$ Solid state nuclear magnetic resonance}

Figure 5(a) exhibits spectra of the protein, the polyphenol and the composites prepared with the later and Mt. The spectra of resveratrol shows in the region 150-160 ppm the three carbons bearing the $\mathrm{OH}$ groups. In the region 101-140 ppm, the peaks are assigned to the carbons of the aromatic cycles and the carbon of the double bond between the two aromatic rings. The spectra of BSA shows a peak at 175.5 ppm while the one of BSA-Mt displays the same peak at 174.8 ppm assigned for backbone carbonyls. Four peaks between 160 and 110 ppm are assigned to aromatic side chain carbons, including in particular the $\mathrm{C}_{\xi}$ from Tyr and Arg residues at 155 $\operatorname{ppm}[20]$. 


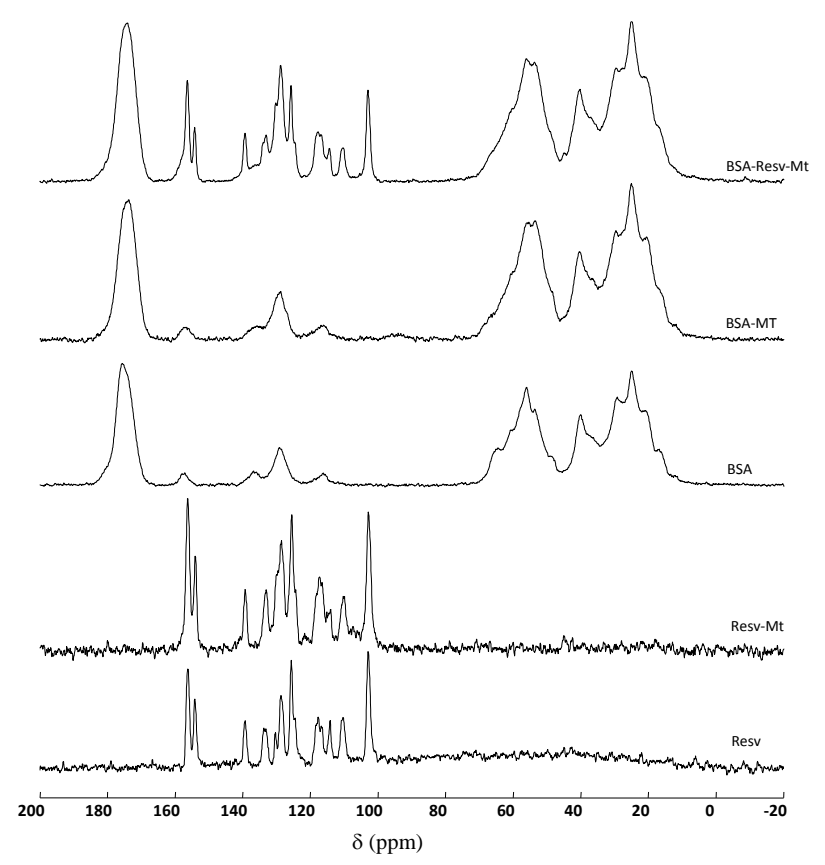

Figure 5(a). ${ }^{13} \mathrm{C}$ CP-MAS NMR spectra with a MAS frequency of $14 \mathrm{kHz}$. Free RESV and free BSA and BSA-Mt, RESV-Mt and BSA-RESV-Mt composites.

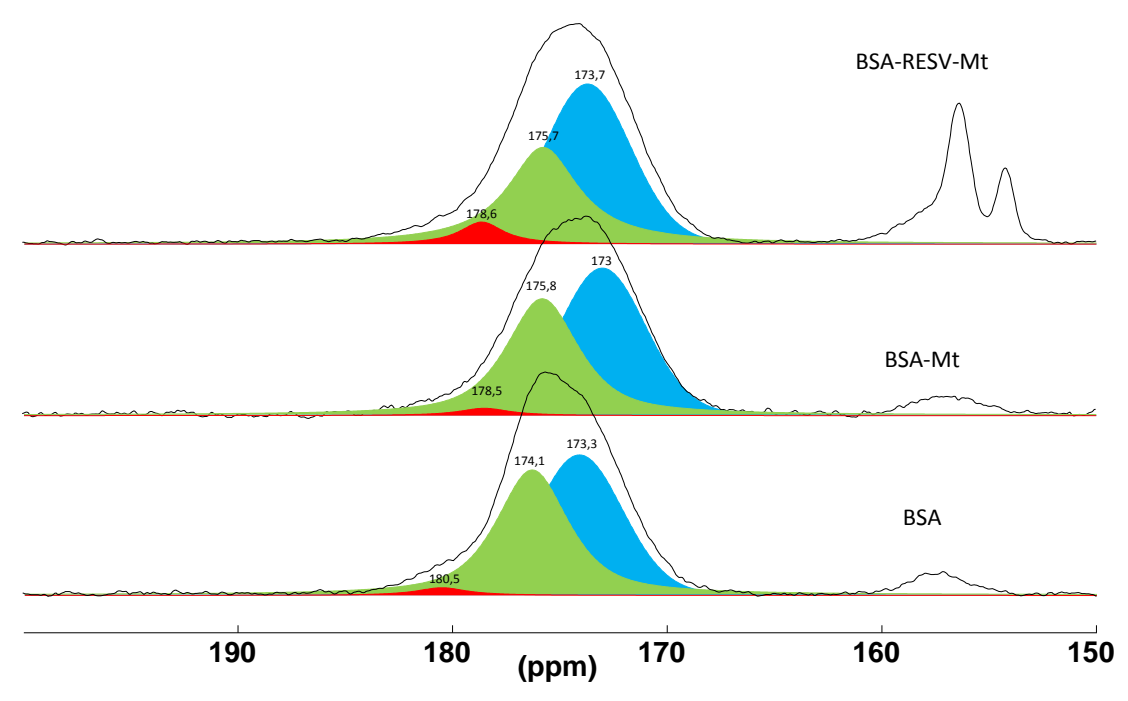

Figure 5(b). Deconvoluted spectra for BSA alone and upon adsorption on montmorillonite and BSARESV-Mt hybrid as illustrated by components attributed to carbonyl peaks.

Figure 5(b) exhibits the decomposition of the spectra for the BSA, BSA-Mt and BSA-RESVMt samples in the region of carbonyl functions, corresponding to two components associated with $\beta$-sheet secondary structures and together $\alpha$-helix and random coil structures [20]. For free BSA the spectrum showed peaks at 180.5; 174.1 and 173.3 ppm. Upon adsorption of protein 
onto Mt, peaks are shifted to 178.5; 175.8 and 173.0 ppm. For the BSA-RESV-Mt composite the shift to 178.6; 175.7 and 173.7 ppm was observed. It must be noted also that resveratrol is significantly co-adsorbed with BSA, as illustrated by the corresponding intense peaks for the spectrum of the BSA-RESV-Mt composite. Together, these results indicate that an interaction between the inorganic surface and the two organic molecules probably takes place leading to a modification of the secondary structure of the protein.

\subsection{Fluorescence spectroscopy}

The fluorescence is an interesting method to characterize the interaction between resveratrol and protein [29,32,33,51]. The BSA contains 2 Trp residues. Trp212 is located within a hydrophobic binding pocket of the protein and Trp134 is located on the surface of the molecule [44,52]. BSA and resveratrol thus exhibit different photophysical properties. The resveratrol absorbance spectrum covers the emission of the BSA. This induces a fluorescence quenching of the BSA in presence of resveratrol due to a non-radiation energy transfer $[53,54]$. The adsorption mechanism is not totally elucidated since two assumptions have been formulated: (i) The BSA and resveratrol are adsorbed independently or (ii) the BSA binds the resveratrol.

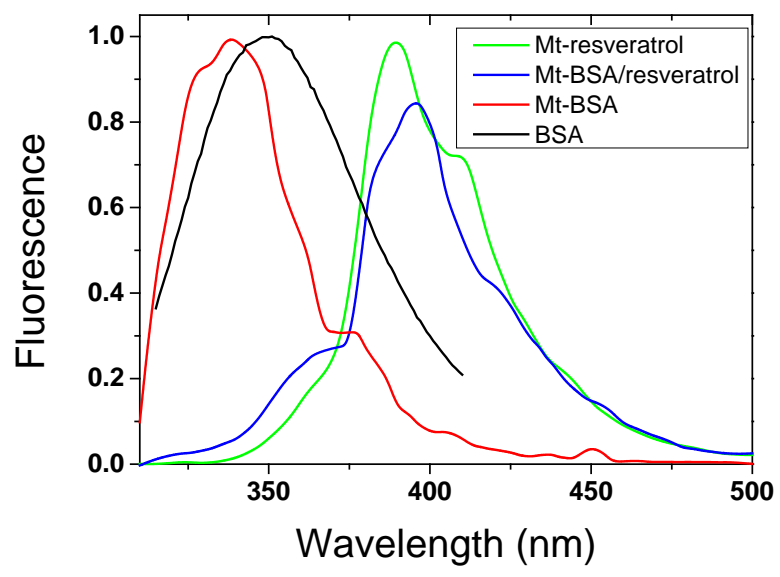

Figure 6(a). Fluorescence emission spectra of free BSA(black) and RESV-Mt (green), BSA-Mt(red) and BSA-RESV-Mt (blue) hybrids. 

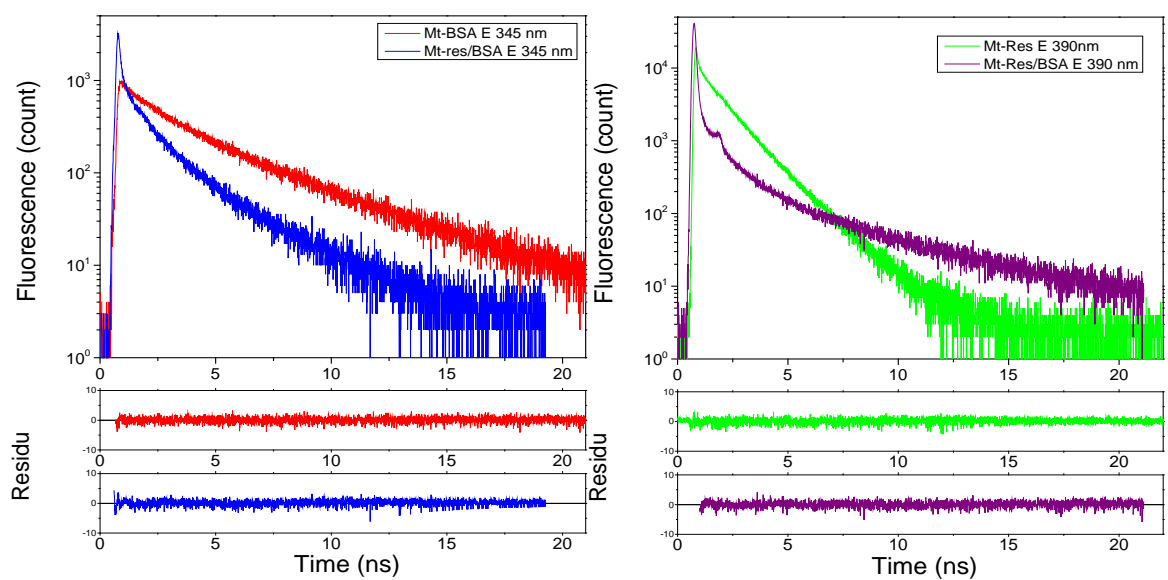

Figure 6(b). Fluorescent decay of BSA-Mt (red), RESV-Mt (green), BSA-RESV-Mt (blue and violet) hybrids.

The fluorescence emission spectra and the decay function are shown in Figure 6(a) and 6(b). The results are reported in table II. In solution, BSA exhibits a maximum of fluorescence emission at $350 \mathrm{~nm}$ and an average fluorescence lifetime $\tau_{a v}$ of $5.83 \mathrm{~ns}$. The fluorescence decay requires three components to be fitted $\tau_{1}=6.287 \mathrm{~ns}, \tau_{2}=2.359$ ns and $\tau_{3}=0.189$ ns. After loading on Mt, the emission spectrum of BSA is shifted to $330 \mathrm{~nm}$ and the average fluorescence lifetime decreases ( $\tau_{a v} 3.667 \mathrm{~ns}$ ). This result emphasizes a modification of Trp environment likely due to the modification of BSA structure as shown in ATR-Infrared and suggests the organic-inorganic interactions. Under excitation at $340 \mathrm{~nm}$, resveratrol has a maximum emission around $390 \mathrm{~nm}$ and a very short fluorescence lifetime in water (40 ps). When it is loaded on Mt, its average lifetime is longer (1.193 ns) due to its interaction with the inorganic material.

Table II. Time resolved fluorescence results for free BSA and BSA-Mt, RESV-Mt and BSA-RESV-Mt hybrids.

\begin{tabular}{|l|r|r|ll|ll|ll|l|l|}
\hline & $\lambda_{\mathrm{Ex}}(\mathrm{nm})$ & $\lambda_{\mathrm{Em}}(\mathrm{nm})$ & $\begin{array}{l}\tau_{1} \\
(\mathrm{~ns})\end{array}$ & $\left(Y_{1} \%\right)$ & $\tau_{2}(\mathrm{~ns})$ & $\left(Y_{2} \%\right)$ & $\tau_{3}(\mathrm{~ns})$ & $\left(Y_{3} \%\right)$ & $\tau_{\mathrm{av}}(\mathrm{ns})$ & $\chi^{2}$ \\
\hline BSA & 290 & 340 & 6.287 & $(88.8)$ & 2.359 & $(10.7)$ & 0.189 & $(0.6)$ & 5.833 & 1.01 \\
\hline BSA-Mt & 290 & 340 & 4.556 & $(71.8)$ & 1.553 & $(24.6)$ & 0.427 & $(3.7)$ & 3.667 & 1.18 \\
\hline RESV-Mt & 340 & 390 & 1.517 & $(33.4)$ & 0.808 & $(42.4)$ & 0.123 & $(24.2)$ & 1.193 & .93 \\
\hline
\end{tabular}




\begin{tabular}{|l|r|r|rl|ll|ll|l|l|}
\hline $\begin{array}{l}\text { BSA- } \\
\text { RESV-Mt }\end{array}$ & 290 & 390 & 4.917 & $(35.0)$ & 1.086 & $(45.8)$ & 0.19 & $(19.2)$ & 2.254 & 1.64 \\
\hline $\begin{array}{l}\text { BSA- } \\
\text { RESV-Mt }\end{array}$ & 290 & 340 & 2.587 & $(42.3)$ & 0.68 & $(28.6)$ & 0.04 & $(29.0)$ & 1.302 & 1.33 \\
\hline
\end{tabular}

The fluorescence emission spectra of BSA-RESV-Mt composite exhibits a similar emission spectra that RESV-Mt under excitation at $290 \mathrm{~nm}$. At the maximum of emission wavelength (390 nm), the average fluorescence lifetime $2.254 \mathrm{~ns}$ is longer than the one of RESV-Mt (under excitation $340 \mathrm{~nm}$ ). The emission band of BSA has disappeared meaning that the Trp fluorescence is quenched by the polyphenol. In addition, we can observe a decrease of fluorescence lifetime to $1.302 \mathrm{~ns}$ measured at $340 \mathrm{~nm}$. The fluorescence quenching of BSA is explained by a non-radiation energy transfer. The lifetime values of BSA-RESV-Mt $\tau_{1}=2.587$ $\mathrm{ns}, \tau_{2}=0.680 \mathrm{~ns}, \tau_{3}=0.03 \mathrm{~ns}$ are different from those of BSA-Mt, suggesting that the adsorbed BSA conformation is different in presence of RESV. Both fluorescence quenching and the different fluorescence lifetime of BSA indicates that RESV can interact with protein and quench its intrinsic fluorescence and also confirm that a complex between resveratrol and BSA occurred [46]. Thus the most likely scenario is a binding of resveratrol by BSA before the adsorption onto montmorillonite.

\section{Conclusion}

The use of montmorillonite as a fining agent in winemaking adsorbed protein thus decreasing turbidity or haze formation and can modulate the polyphenol concentration of wine. The results suggest a non denaturated intercalation of the protein in the interlayer space of montmorillonite by electrostatic forces and hydrogen bonding causing delamination and/or partial exfoliation of the layers of clay mineral observed in XRD and TEM. The direct interaction of resveratrol with montmorillonite can also be observed. It can be located on the surface and the edges of the clay 
mineral. Extensive penetration of the protein and resveratrol together causes exfoliation of the lamellar structure of the montmorillonite. Time resolved fluorescence experiments highlight the strong interaction between resveratrol and BSA and changes in the environment of amino acid residues due to energy transfer from Trp to resveratrol. This is the first example of coadsorption of a polyphenol and protein in presence of montmorillonite. Current studies are under progress to transpose this work on a real wine solution.

\section{Acknowledgements}

This is work was supported by Capes/Cofecub Project (N 835/15) as well as with participation of the Archeology Molecular and Structural Laboratory and National School of Chemistry of Montpellier, in France and Fuel and Material Laboratory and Fast Solidification Laboratory, in Brazil.

\section{References}

[1] N. Jaeckels, S. Tenzer, M. Meier, F. Will, H. Dietrich, H. Decker, P. Fronk, Influence of bentonite fining on protein composition in wine, LWT - Food Science and Technology, 75 (2017) 335-343.

[2] S.C. Van Sluyter, J.M. McRae, R.J. Falconer, P.A. Smith, A. Bacic, E.J. Waters, M. Marangon, Wine protein haze: Mechanisms of formation and advances in prevention, Journal Agricultural and Food Chemistry, 63 (2015) 4020-4030.

[3] M. V. Moreno-Arribas, E. Pueyo, M.C. Polo, Analytical methods for the characterization of proteins and peptides in wines, Analytica Chimica Acta, 2002. 458 (2002) 63-75.

[4] R. Dordoni, D. Colangelo, M. Giribaldi, M.G. Giuffrida, D.M. De Faveri, M. Lambri, Effect of bentonite characteristics on wine proteins, polyphenols, and metals under conditions of different pH, American Journal of Enology and Viticulture, 66 (2015) 518- 
530.

[5] S. Vincenzi, A. Panighel, D. Gazzola, R. Flamini, A. Curioni, Study of combined effect of proteins and bentonite fining on the wine aroma loss, Journal of Agricultural and Food Chemistry 63 (2015) 2314-2320.

[6] M. Esteruelas, N. Kontoudakis, M. Gil, M.F. Fort, J.M. Canals, F. Zamora, Phenolic compounds present in natural haze protein of Sauvignon white wine, Food Reserach Internatinal, 44 (2011) 77-83.

[7] C. Cilindre, E. Fasoli, A. D’Amato, G. Liger-Belair, P.G. Righetti, It’s time to pop a cork on champagne’s proteome!, Journal of Proteomics, 105 (2014) 351-362.

[8] P. Wigand, S. Tenzer, H. Schild, H. Decker, Analysis of Protein Composition of Red Wine in Comparison with Rosé and White Wines by Electrophoresis and High-Pressure Liquid Chromatography-Mass Spectrometry (HPLC-MS), Journal of Agricultural and Food Chemistry, 57 (2009) 4328-4333.

[9] S. Pérez-Magariño, M.L. González-San José, Polyphenols and colour variability of red wines made from grapes harvested at different ripeness grade, Food Chemistry, 96 (2006) 197-208.

[10] H. Cao, X. Jia, J. Shi, J. Xiao, X. Chen, Non-covalent interaction between dietary stilbenoids and human serum albumin: Structure-affinity relationship, and its influence on the stability, free radical scavenging activity and cell uptake of stilbenoids, Food Chemistry, 202 (2016) 383-388.

[11] R. Lu, G. Serrero, Resveratrol, a natural product derived from grape, exhibits antiestrogenic activity and inhibits the growth of human breast cancer cells (1999) Journal of Cellular Physiology - Wiley Online Library, 304 (1999) 297-304.

[12] E. Wenzel, V. Somoza, Metabolism and bioavailability of trans-resveratrol, Molecular 
Nutrition and Food Research, 49 (2005) 472-481.

[13] R.C. Minussi, M. Rossi, L. Bologna, L. Cordi, D. Rotilio, G.M. Pastore, N. Durán, Phenolic compounds and total antioxidant potential of commercial wines, Food Chemistry, 82 (2003) 409-416.

[14] C. Lucas-Abellán, I. Fortea, J.M. López-Nicolás, E. Núñez-Delicado, Cyclodextrins as resveratrol carrier system, Food Chemistry, 104 (2007) 39-44.

[15] T. Richard, D. Lefeuvre, A. Descendit, S. Quideau, J.P. Monti, Recognition characters in peptide-polyphenol complex formation, Biochimica and Biophysica Acta , 1760 (2006) 951-958.

[16] F. Achaerandio, I., Pacova, V., Lopez, Protein Adsorption by Bentonite in a white wine model solution: Effect of Protein Molecualr Weight and Ethanol Concentration, American Journal of Enology and Viticulture, 52 (2001) 122-126.

[17] M. Jaber, J. Miehé-Brendlé, Synthesis, characterization and applications of 2:1 phyllosilicates and organophyllosilicates: Contribution of fluoride to study the octahedral sheet, Microporous Mesoporous Materials, 107 (2008) 121-127.

[18] M.F. Brigatti, E. Galan, B.K.G. Theng, Chapter 2 Structures and Mineralogy of Clay Minerals, Developments Clay Science, 1 (2006) 19-86.

[19] M. Jaber, J. Miehe-Brendle, R. Le Dred, Mercaptopropyl Al-Mg phyllosilicate: synthesis and characterization by XRD, IR, and NMR, Cheistry. Leters,. 31 (2002) 954955.

[20] A. Assifaoui, L. Huault, C. Maissiat, C. Roullier-Gall, P. Jeandet, J. Hirschinger, J. Raya, M. Jaber, J.-F. Lambert, P. Cayot, R.D. Gougeon, C. Loupiac, Structural Studies of Adsorbed Protein (Betalactoglobulin) on Natural Clay (Montmorillonite), RSC Advances, 4 (2014) 61096-61103. 
[21] W.H. Yu, N. Li, D.S. Tong, C.H. Zhou, C.X. Lin, C.Y. Xu, Adsorption of proteins and nucleic acids on clay minerals and their interactions: A review, Appied. Clay Scence,. 80-81 (2013) 443-452.

[22] S. Servagent-Noinville, M. Revault, H. Quiquampoix, M. Baron, Conformational Changes of Bovine Serum Albumin Induced by Adsorption on Different Clay Surfaces: FTIR Analysis., Journal of Colloid and Interface Science, 221 (2000) 273-283.

[23] P. Kumar, K.P. Sandeep, S. Alavi, V.D. Truong, R.E. Gorga, Effect of Type and Content of Modified Montmorillonite on the Structure and Properties of Bio-Nanocomposite Films Based on Soy Protein Isolate and Montmorillonite, Journal of Food Science, 75 (2010) 46-56.

[24] T.G. Gopakumar, J.A. Lee, M. Kontopoulou, J.S. Parent, Influence of clay exfoliation on the physical properties of montmorillonite / polyethylene composites, Polymer,43 (2002) 5483-5491.

[25] P. Cai, Q. Huang, X. Zhang, H. Chen, Adsorption of DNA on clay minerals and various colloidal particles from an Alfisol, Soil of Biology and Biochemistry, 38 (2006) 471476.

[26] J.L. Donovan, J.C. Mccauley, N.T. Nieto, A.L. Waterhouse, Effects of Small-Scale Fining on the Phenolic Composition and Antioxidant Activity of Merlot Wine, ACS Symposium Series, (1999) 142-155.

[27] R.T. Threlfall, J.R. Morris, a. Mauromoustakos, Effects of fining agents on transresveratrol concentration in wine, Australian Journal of Grape and Wine Research, 5 (1999) 22-26.

[28] L. Liang, H. a Tajmir-Riahi, M. Subirade, Interaction of b-lactoglobulin with resveratrol and its biological implications, Biomacromolecules, 9 (2008) 50-56. 
[29] C.N. N' Soukpoé-Kossi, C. St-Louis, M. Beauregard, M. Subirade, R. Carpentier, S. Hotchandani, H.A. Tajmir-Riahi, Resveratrol Binding to Human Serum Albumin, Journal of Biomolecular Structure and Dyamics, 243 (2006) 277-283.

[30] P. Bourassa, J. Bariyanga, H.A. Tajmir-Riahi, Binding sites of resveratrol, genistein, and curcumin with milk $\alpha$ - And $\beta$-caseins, Journal of Physical Chemistry, B. 117 (2013) 1287-1295.

[31] D.C. Carter, J.X. Ho, Structure of serum albumins, Advances in Protein Chemistry, 45 (1994) 153-203.

[32] M.S. Nair, Journal of Photochemistry and Photobiology B : Biology Spectroscopic study on the interaction of resveratrol and pterostilbene with human serum albumin, Journal of Photochemistry and Photobiology B : Biology, 149 (2015) 58-67.

[33] X.Y. Jiang, W.X. Li, H. Cao, Study of the interaction between trans-resveratrol and BSA by the multi-spectroscopic method, Journal of Solution Chemistry, 37 (2008) 16091623.

[34] M. Jaber, T. Georgelin, H. Bazzi, F. Costa-torro, G. Clodic, Selectivities in Adsorption and Peptidic Condensation in the (Arginine and Glutaminic Acid)/Montmorillonite Clay System, Journal of Physical Chemistry C, 118 (2014) 25447-25455.

[35] V. Tangaraj, J. Janot, M. Jaber, M. Bechelany, S. Balme, Adsorption and photophysical properties of fluorescent dyes over montmorillonite and saponite modified by surfactant, Chemosphere, (2017).

[36] S. Balme, J.M. Janot, P. Déjardin, P. Seta, Highly efficient fluorescent label unquenched by protein interaction to probe the avidin rotational motion, Journal of Photochemical and Photobiology A Chemistry, 184 (2006) 204-211.

[37] A.K. Bajpai, R. Sachdeva, Study on the adsorption of hemoglobin onto bentonite clay 
surfaces, Journal of Applied Polymer Science, 85 (2002) 1607-1618.

[38] M. Lepoitevin, M. Jaber, R. Guégan, J.M. Janot, P. Dejardin, F. Henn, S. Balme, BSA and lysozyme adsorption on homoionic montmorillonite: Influence of the interlayer cation, Applied Clay Science, 95 (2014) 396-402.

[39] M. Reinholdt, J. Miehé-Brendlé, L. Delmotte, R. Le Dred, M.-H. Tuilier, Synthesis and characterization of montmorillonite-type phyllosilicates in a fluoride medium, Clay Minerals, 40 (2005) 177-190.

[40] V. Bertacche, N. Lorenzi, D. Nava, E. Pini, C. Sinico, Host-guest interaction study of resveratrol with natural and modified cyclodextrins, Journal of Inclusion Phenomena Macrocyclic Chemistry, 55 (2006) 279-287.

[41] M. Popova, A. Szegedi, V. Mavrodinova, N. Novak, J. Mihály, S. Klébert, N. Benbassat, K. Yoncheva, Preparation of resveratrol-loaded nanoporous silica materials with different structures, Journal of Solid State Chemistry, 219 (2014) 37-42.

[42] T. Georgelin, M. Jaber, T. Onfroy, A.A. Hargrove, F. Costa-Torro, J.F. Lambert, Inorganic phosphate and nucleotides on silica surface: Condensation, dismutation, and phosphorylation, Journal of Physical Chemistry C, 117 (2013) 12579-12590.

[43] J. Madejová, FTIR techniques in clay mineral studies, Vibrational Spectroscopy, 31 (2003) 1-10.

[44] P. Bourassa, C.D. Kanakis, P. Tarantilis, M.G. Pollissiou, H.A. Tajmir-Riahi, Resveratrol, genistein, and curcumin bind bovine serum albumin, Journal of Physical Chemistry B, 114 (2010) 3348-3354.

[45] D. Roy, S. Dutta, S.S. Maity, S. Ghosh, A. Singha Roy, K.S. Ghosh, S. Dasgupta, Spectroscopic and docking studies of the binding of two stereoisomeric antioxidant catechins to serum albumins, Journal of Lumininescence, 132 (2012) 1364-1375. 
[46] X. Liu, Y. Shang, X. Ren, H. Li, Molecular Modeling and Spectroscopic Studies on the Interaction of Transresveratrol with Bovine Serum Albumin, Journal of Chemistry, 2013 (2013).

[47] F. Billes, I. Mohammed-Ziegler, H. Mikosch, E. Tyihák, Vibrational spectroscopy of resveratrol, Spectrochimica Acta - Part A Molecular and Biomolecular Spectroscopy, 68 (2007) 669-679.

[48] V. Della Porta, E. Bramanti, B. Campanella, R. Tin, C. Duce, RSC Advances Conformational analysis of bovine serum albumin adsorbed on halloysite nanotubes and kaolinite: a Fourier transform infrared spectroscopy study, RSC Advances, 5 (2016) 72386-72398.

[49] W. Xie, Z. Gao, K. Liu, W.P. Pan, R. Vaia, D. Hunter, A. Singh, Thermal characterization of organically modified montmorillonite, Thermochiica Acta. 367-368 (2001) 339-350.

[50] C. Duce, V. Della Porta, E. Bramanti, B. Campanella, A. Spepi, M.R. Tiné, Loading of halloysite nanotubes with BSA, $\alpha$-Lac and $\beta$-Lg: A Fourier transform infrared spectroscopic and thermogravimetric study, Nanotechnology, 28 (2017) 055706.

[51] S. Balme, R. Guégan, J.-M. Janot, M. Jaber, M. Lepoitevin, P. Dejardin, X. Bourrat, M. Motelica-Heino, Structure, orientation and stability of lysozyme confined in layered materials, Soft Matter, 9 (2013) 3188.

[52] N. Poklar, Interactions of different polyphenols with bovine serum albumin using fluorescence quenching and molecular docking, Food Chemistry,135 (2012) 2418-2424.

[53] J.B. Xiao, X.Q. Chen, X.Y. Jiang, M. Hilczer, M. Tachiya, Probing the interaction of trans-resveratrol with bovine serum albumin: A fluorescence quenching study with tachiya model, Journal of Fluorescence, 18 (2008) 671-678. 
[54] S. Cao, D. Wang, X. Tan, J. Chen, Interaction between trans-resveratrol and serum albumin in aqueous solution, Journal of Solution Chemistry, 38 (2009) 1193-1202. 


\section{Supplementary information :}

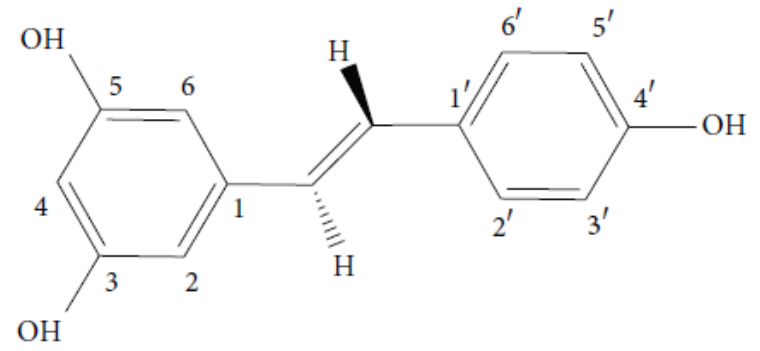

Figure $1 \mathrm{SI}$. Structure of the resveratrol (3,5,4'-trihydroxystilbene)[46].

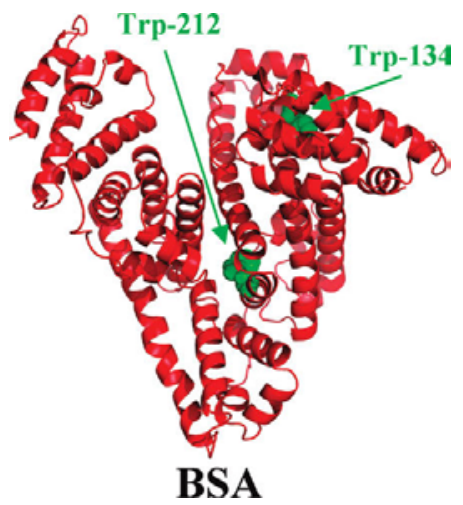

Figure 2 SI. Structure of bovine serum albumin (BSA)[44]. 


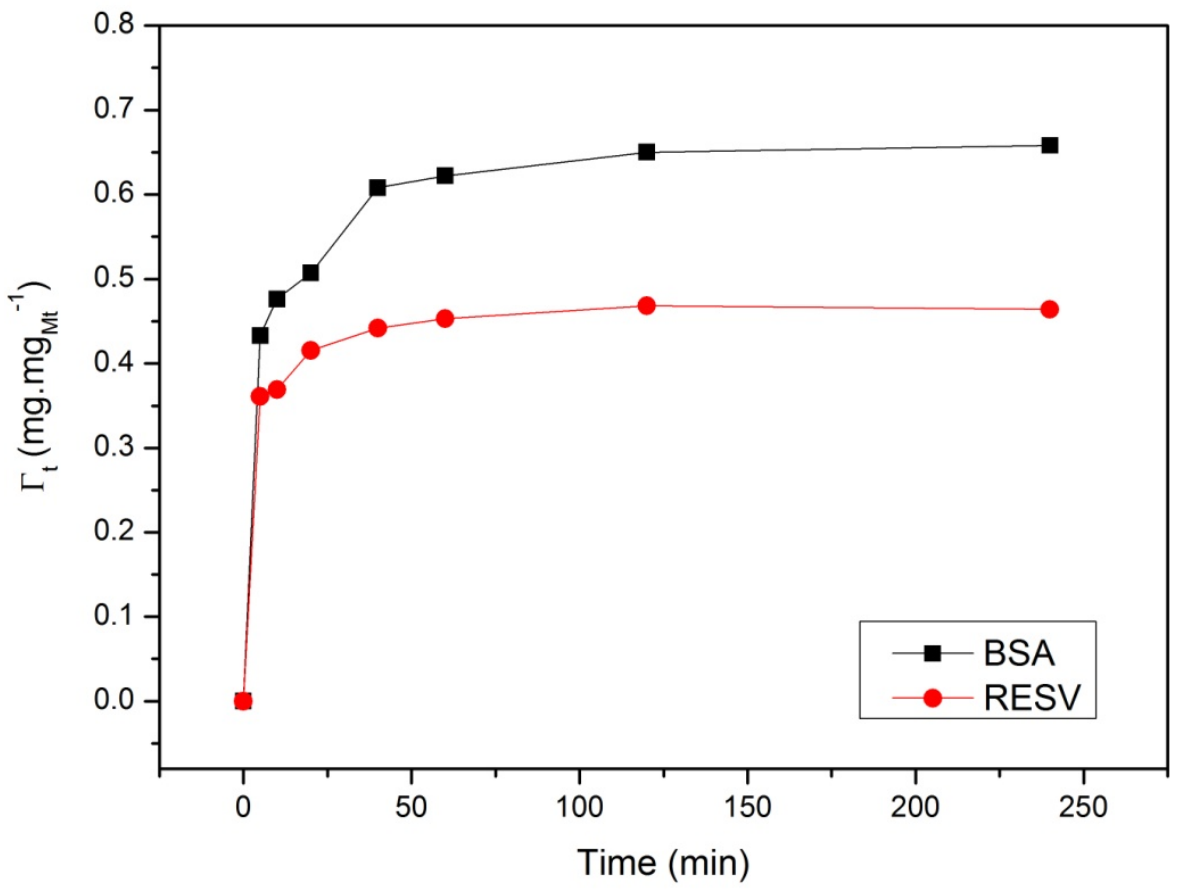

Figure $3 \mathrm{SI}$. Adsorption kinetics of BSA (black) and RESV (red) absorbed on montmorillonite. Experimental conditions: BSA (1.0 mg. mL $\left.{ }^{-1}\right)$, RESV $\left(1.0 \mathrm{mg} \cdot \mathrm{mL}^{-1}\right)$, Mt $\left(1.0 \mathrm{mg} \cdot \mathrm{mL}^{-1}\right)$ in a buffer phosphate at $\mathrm{pH} 4.5$ and ethanolic solution in ratio of $25 \%$. 

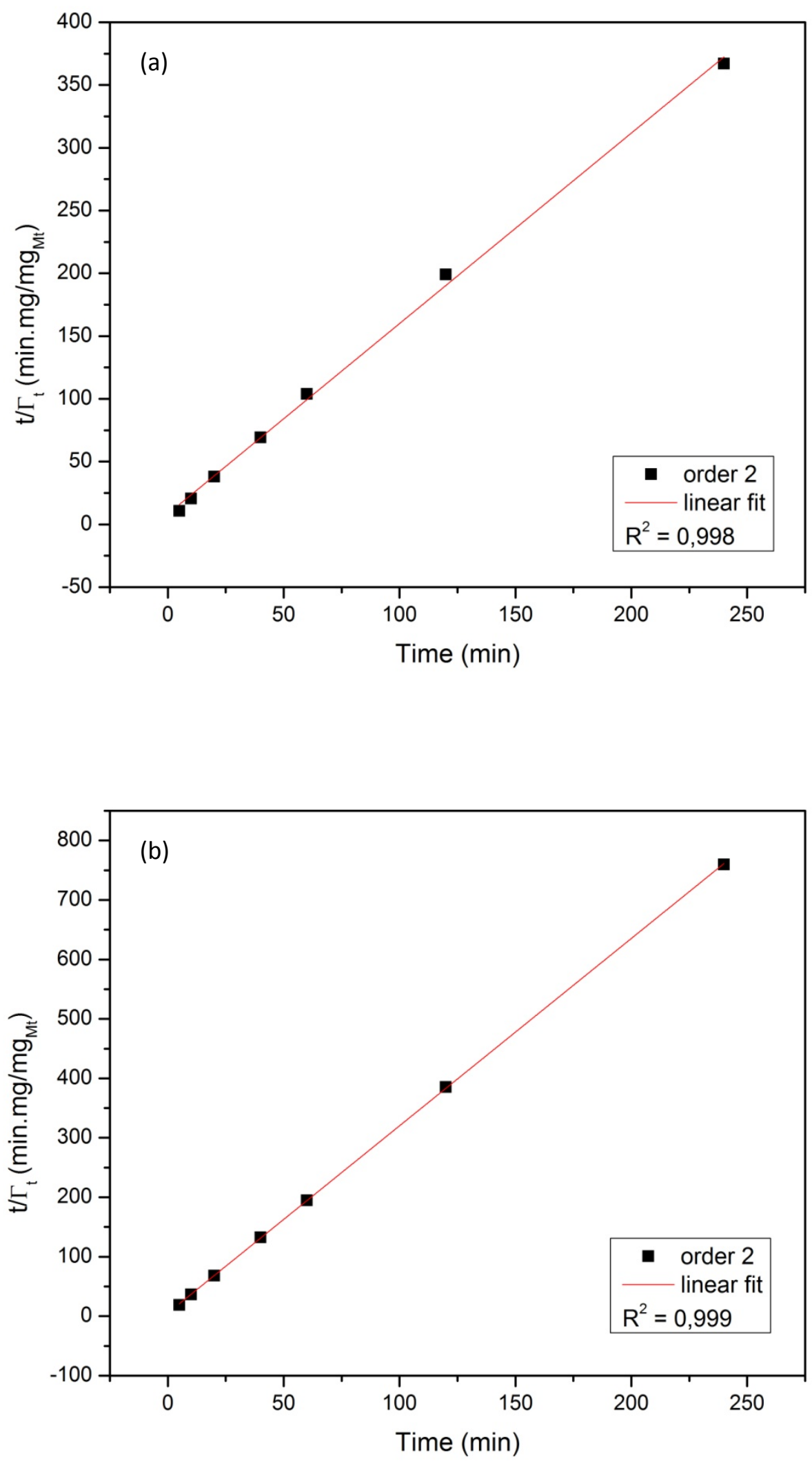

Figure 4 SI. Langmuir isotherms, according to the eqn (2) for pseudo-second-order model, of BSA (a) and Resveratrol (b) for adsorption on montmorillonite. 


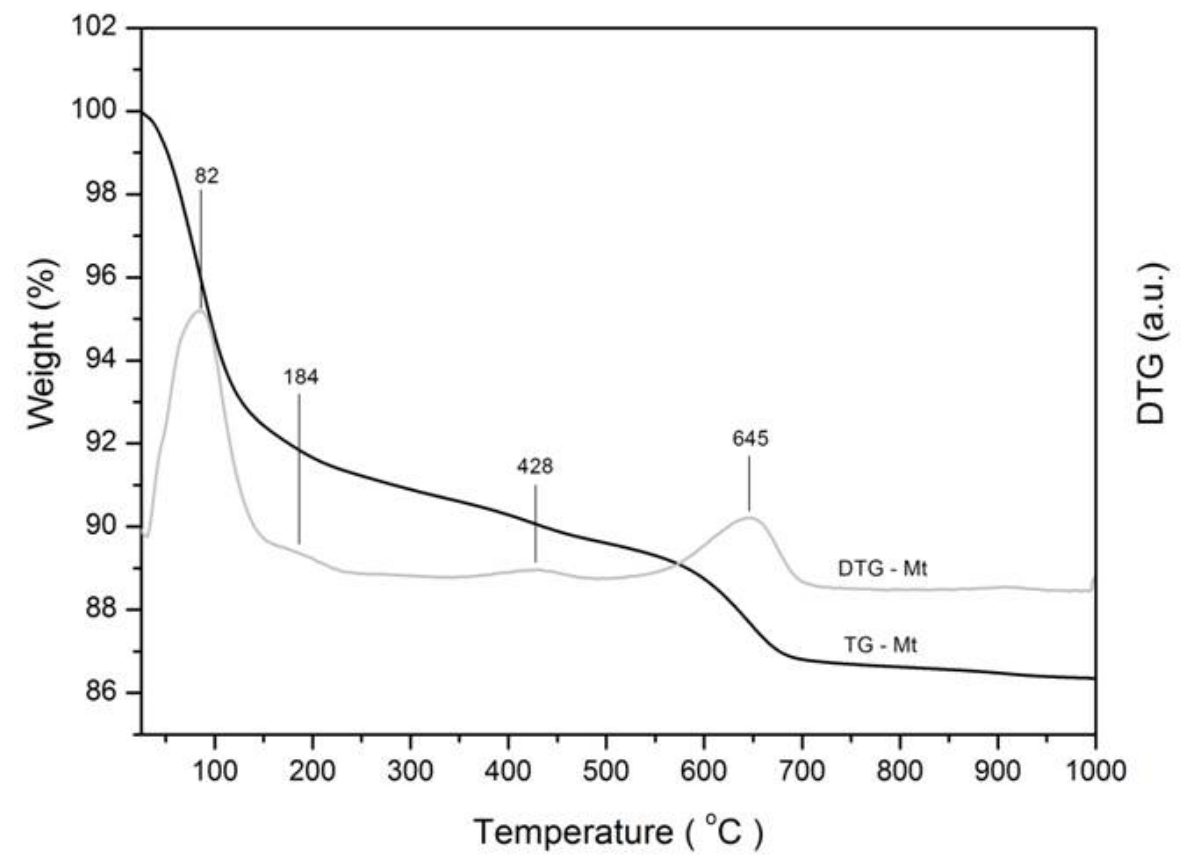

Figure $5 \mathrm{SI}$. TG (black) and DTG (grey) curves of the montmorillonite showing characteristic steps of clay mineral mass loss recorded under air flow at $5{ }^{\circ} \mathrm{C} / \mathrm{min}$.

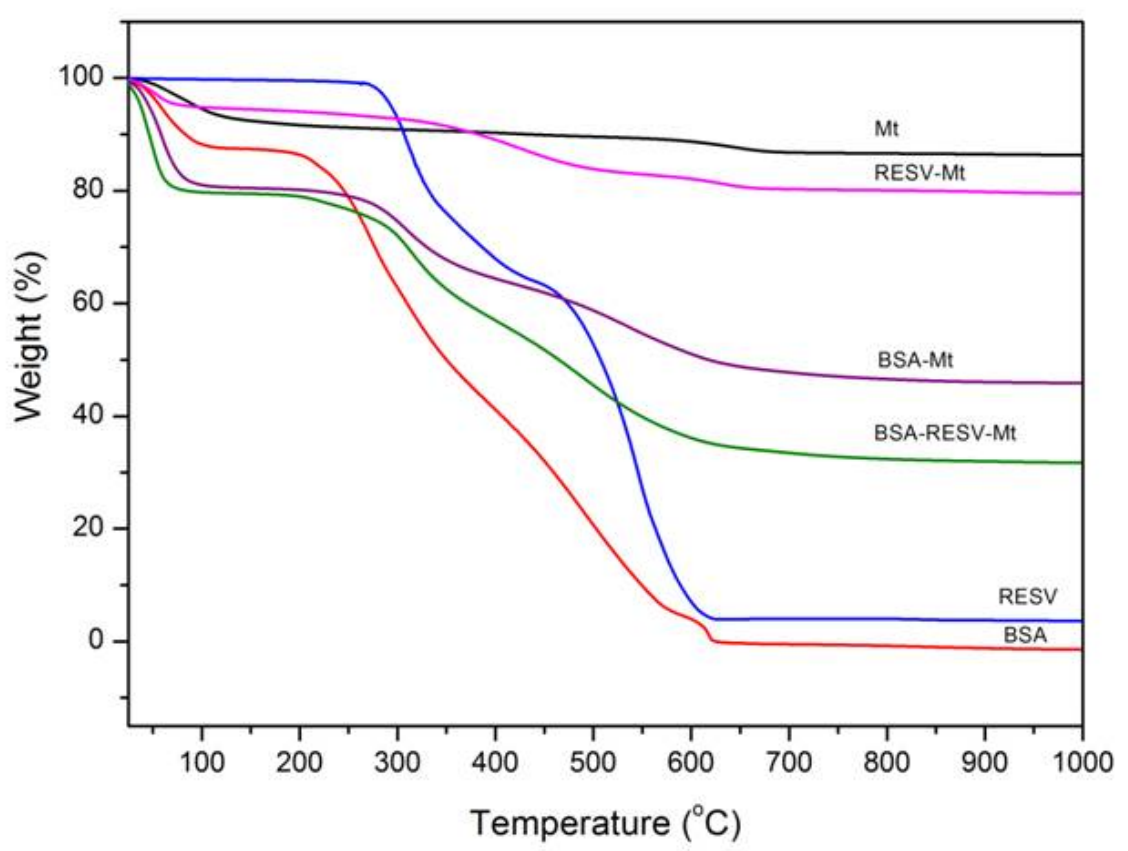

Figure 6 SI. TG curves of the montmorillonite (black), RESV (blue), BSA (red) alone and after adsorption on montmorillonite, where RESV-Mt (pink), BSA-Mt (violet) and BSA-RESV-Mt (green) recorded under air flow at $5{ }^{\circ} \mathrm{C} / \mathrm{min}$. 


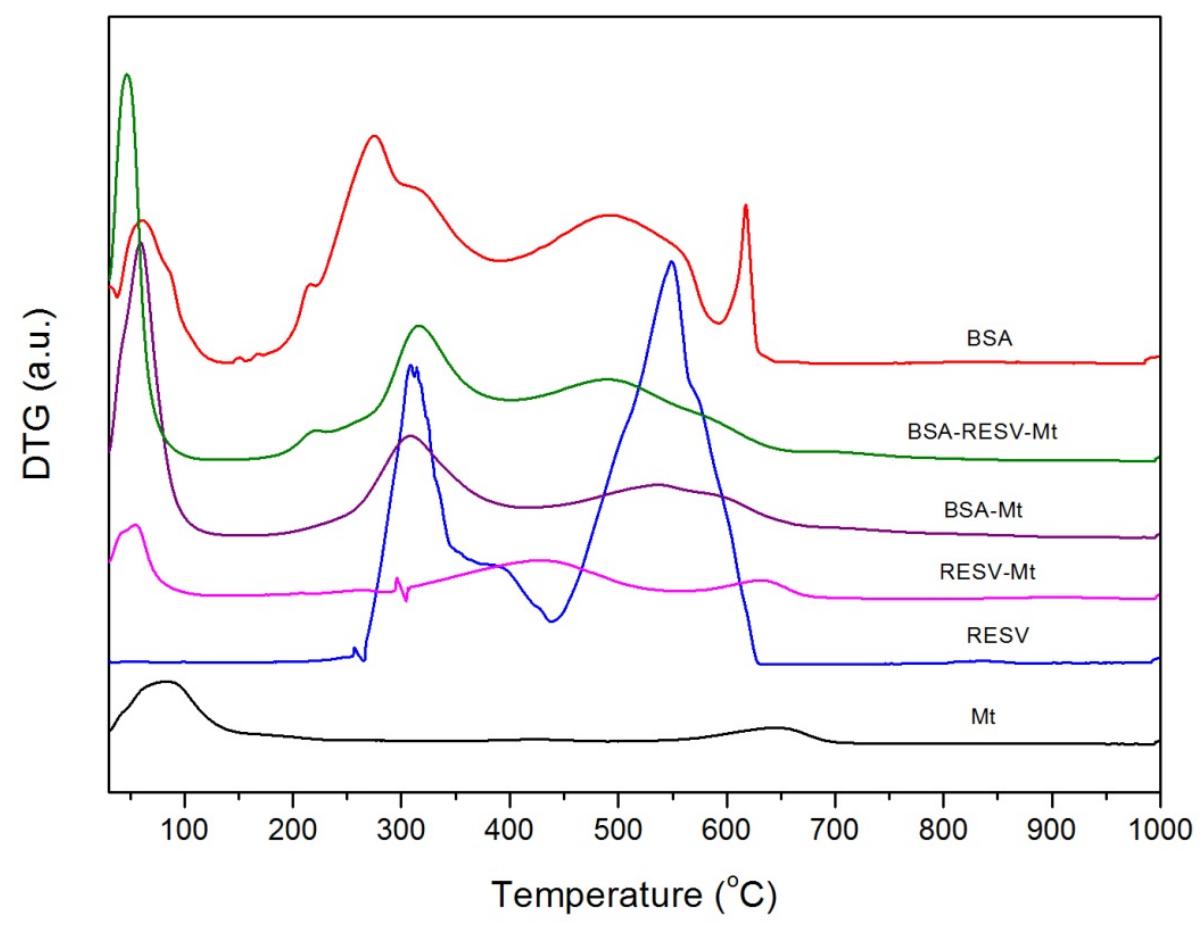

Figure 7 SI. DTG curves of the montmorillonite (black), RESV (blue), BSA (red) alone and upon adsorption on montmorillonite, where RESV-Mt (pink), BSA-Mt (violet) and BSA-RESV-Mt (green). 